\title{
Effect of individual protective behaviors on influenza transmission: an agent-based model
}

\author{
Elnaz Karimi • Ketra Schmitt • Ali Akgunduz
}

Received: 9 October 2013 / Accepted: 5 November 2014 / Published online: 13 January 2015

(C) Springer Science+Business Media New York 2015

\begin{abstract}
It is well established in the epidemiological literature that individual behaviors have a significant effect on the spread of infectious diseases. Agent-based models are increasingly being recognized as the next generation of epidemiological models. In this research, we use the ability of agent-based models to incorporate behavior into simulations by examining the relative importance of vaccination and social distancing, two common measures for controlling the spread of infectious diseases, with respect to seasonal influenza. We modeled health behaviour using the result of a Health Belief Model study focused on influenza. We considered a control and a treatment group to explore the effect of education on people's health-related behaviors patterns. The control group reflects the behavioral patterns of students based on their general knowledge of influenza and its interventions while the treatment group illustrates the level of behavioral changes after individuals have been educated by a health care expert. The results of this study indicate that self-initiated behaviors are successful in controlling an outbreak in a high contact rate location such as a university. Self-initiated behaviors resulted in a population attack rate decrease of $17 \%$ and a $25 \%$ reduction in the peak number of cases. The simulation also provides significant evidence for the effect of an HBM theorybased educational program to increase the rate of applying the target interventions (vaccination by $22 \%$ percent and social distancing by $41 \%$ ) and consequently to control the outbreak.
\end{abstract}

\footnotetext{
E. Karimi · A. Akgunduz

Department of Mechanical and Industrial Engineering, Concordia University, Montreal, QC, Canada

K. Schmitt $(\triangle)$

Centre for Engineering in Society, Concordia University, Montreal, QC, Canada

e-mail: ketra.schmitt@concordia.ca
}

Keywords Influenza $\cdot$ Agent-based simulation $\cdot$ Health belief model $\cdot$ Individual behavior $\cdot$ Effectiveness

\section{Introduction}

Influenza outbreaks are a significant source of morbidity, mortality, hospitalization and work loss every year. These outbreaks lead to approximately 7,000 to 49,000 deaths, 3.1 million hospitalizations and a total economic burden of $\$ 87$ billion in the United States alone [1]. These data clearly indicate that preventing and managing seasonal flu can result in significant public health improvements. Since seasonal influenza is predictable, it has the potential to be controllable with evidenced-based management strategies [2, 3]. While these strategies won't eliminate flu, better management can greatly reduce the number of individuals impacted as well as the severity and duration of illness. The impact of strategies like vaccination, quarantine and school closures on the control of these outbreaks has been extensively studied. However, the approaches that have been studied general fail to consider the self-initiated protective behaviors that individuals develop in the face of an infectious disease.

In the event of a disease outbreak with a high attack rate in a population, it is likely that much of the behavioral control would be done through personal protective behavior, such as vaccination or social distancing. Decreasing the amount of contact between infected and susceptible individuals by encouraging them to avoid crowded places or close physical contact with each other could slow the outbreak and lower its peak [4, 5]. For instance, during 1918 influenza pandemic, people developed self-isolation behaviour and avoided places where they might come into contact with others [6]. A high rate of personal protective behaviors such as vaccination, selfisolation, physical distancing, antiviral drugs, masks etc. in a population could have a significant impact on the severity of 
an outbreak. Therefore understanding the dynamics of these behaviors could provide decision makers with better strategies to mitigate influenza.

Mathematical and simulation models have been developed to understand the dynamics of influenza transmission in terms of mortality rate, hospitalization rate, total number of infected individuals, number of newly infected per day, outbreak peak period, etc. These models, however, do not study the dynamics of influenza transmission at the individual level. Researchers are increasingly using agent based simulations (ABS) to incorporate the social, environmental, physical, and economic characteristics of individuals in a population into influenza transmission models [7, 8]. In this paper we develop an agent-based simulation to understand the impact of self-initiated protective behaviors on the spread of influenza within a university population. This simulation allows us to study the impacts of population-specific social, environmental and psychological characteristics on an influenza outbreak. We then examine the effect of an educational program to improve the willingness of individuals to apply protective behaviors and consequently better mitigate the outbreak.

A hallmark of educational experience is the frequent interactions between students which can lead to a high attack rate not only in school but also in students' and teachers' households. Occurrence of outbreak in schools causes a significant increase in student health care visits, medication usage, absenteeism and work loss [9]. Given their high attack rates, schools are an ideal place for the development of interventions and health promotion programs to prevent influenza [5]. Delivering such programs in schools can also alleviate many of the common barriers of community-based treatments, such as time, location, transportation and cost [10].

One of the challenges in developing an agent-based simulation is to identify the psychological variables that play a part in individuals' decision making process to develop these behaviors. To overcome this challenge we conduct a crosssectional study using the Health Belief Model (HBM). Students from the Faculty of Engineering and Computer Science undergraduate population at Concordia University participated in the study. The objective of the cross-sectional study is to investigate students' perceptions of the influenza virus and identify the factors that impact individual intention to develop the two main protective behaviors (vaccination and social distancing) toward influenza. The health-behavior patterns obtained from this study are then incorporated into the simulation to estimate the probabilities of developing social distancing and vaccination through the flu season for each individual. This simulation model provides policy makers with a working tool to first understand population behavior toward influenza in a specific environment and then allow them to instruct and evaluate educational programs to mitigate flu.

The remainder of the paper is organized as follows. In section 2, the relevant literature is discussed. Details of the agent-based simulation and how it can be utilized for influenza prevention and control are given in section 3. Results of experiments with university students are discussed in section 4. Finally, conclusions and proposed future-work are given in section 5 .

\section{Literature review}

Psychologists have developed a variety of models to explain individuals' attitudes and beliefs toward their health and how to implement educational strategies to change health behaviors. Such models, known as value-expectancy theories, are based on the idea that individuals expect specific outcomes for their actions [11]. HBM is one of the most well-known valueexpectancy theories that emphasize two variables: 1) the value an individual places on a specific outcome; and 2) the likelihood that individual considers for a behavior to result in that outcome. The following factors are used to construct HBM: perceived susceptibility to disease, perceived severity of disease, perceived benefits of protective behavior and perceived barriers to protective behavior [12]. Perceived susceptibility measures the extent to which one feels he or she is susceptible to a disease or condition. Perceived severity measures to what degree one believes a condition would impact one's health. Perceived benefits are the extent to which one believes a given behavior will reduce susceptibility to, or severity of, a disease. Perceived barriers measures the level of costs (physical or psychological) that one believes acting would require. Since some or all of these factors work together to result in a specific behavior, they all should be considered to predict or explain individual behavior. Therefore, it is important to assess and explore these factors in an individual level to predict and understand the health related behaviors of a certain population.

HBM has been previously used to study beliefs and behaviors toward influenza virus vaccination [13-15]. Painter et al. developed a school-based educational program constructed from the HBM toward seasonal flu vaccination for a year, which led to a significant increase of vaccination rates among middle and high school students [16]. Durham et al. investigated the effect of HBM variables on two protective behaviors toward influenza: vaccination and avoiding crowded places. This study indicated that all HBM variables except perceived susceptibility were significant predictors of vaccination while avoiding crowded places was only correlated with the perceived benefits of this behavior [17].

Agent-Based Modeling and Simulation (ABMS) is a relatively new approach in modeling infectious diseases. In these simulations, individuals in a population, known as "agents", have distinct behaviors and interact with each other. These social interactions in turn influence agent behaviors over time. Modeling the transmission of an infectious disease using 
ABMS helps researchers to understand the effects of such diversity of behaviors and attributes between individuals and also the effects that interactions among agents have on the transmission of disease within the population as a whole. The first attempts to develop an agent-based pandemic simulation model were in 1976, when Elveback developed an ABS to model the 1918 Pandemic Influenza [18]. This study modeled the interaction of 1000 people in the community, mixed in different groups such as family, neighborhoods and schools and defined the transmission risk as a function of contact time between individuals. Age-specific transmission hazard rates were obtained from the patterns observed in the 1968 and 1957 pandemics. Behavioral changes such as contact reduction and quarantine for school children were also considered in the model. All subsequent studies that adopt an ABMS approach, or an approach that considers non-homogeneous population to model an infectious disease outbreak, have many core features of this study. Another good example of earlier agent-based models was the model developed by Halloren et al. in 2002, which estimated the effectiveness of interventions such as vaccination in keeping the attack rate of an epidemic below a pre-defined limit in a virtual population with 2,000 agents [19].

ABMS approaches have been extended to study both the transmission of disease and the effect of interventions within larger populations under bioterrorism attack [20-22]. A good example of such simulations was EpiSimS, developed by Los Alamos National Laboratory, to simulate the spread of pandemic influenza in the Greater Los Angeles area with over 18 million agents in over half a million geographic sub-locations. The hour-by-hour contact patterns used in EpiSimS were obtained from the United States National Household Travel Survey by recording the movement of people through different locations during sampled days. EpiSims was used in several studies to explore the effect of various interventions strategies on the spread of disease. For example one study found that school closures did not have a strong effect on a pandemic's attack rate, rather they delayed the pandemic's peak [23]. Another study involving EpiSimS showed that the combination of school closures and antiviral treatments were successful in significantly reducing the infection rate before the vaccine became available [24]. Das et al. developed another large scale epidemic simulation in 2008 with over 1.1 million agents to help healthcare executives develop mitigation strategies related to vaccination, prophylaxis, social distancing and hospital admission by incorporating a variety of decision factors [21].

\section{Methodology}

In order to test the impact of self-initiated protective behaviors (vaccination and social distancing) and educational programs on seasonal influenza outbreaks, we applied an agent-based simulation to model a virtual replication of influenza outbreak in a university setting. The synthetic population was constructed to match the population of Concordia University's undergraduate engineering students at the time. Other inhabitants such as faculty, staff, visitors and graduate students were not considered in this simulation. Undergraduate student behaviors toward influenza and student peer interactions were studied extensively. Once student behaviors and interactions with each other on campus were captured, a discrete system simulation model that imitated the physical geography of the Montreal downtown campus of Concordia University and the behaviors and interactions of students on campus was developed. After verifying the accuracy of the model, two intervention strategies were tested and results were compared. Figure 1 illustrates the development of the proposed agent based influenza control and prevention methodology. The proposed agent based simulation model relies on thorough understanding of student's social behavior in and around campus, student protective behaviors toward influenza and influenza-related information. This information is collected through three main sources of input described in Fig. 1; university's database, influenza literature and a cross-sectional study within the target population. Key disease parameters used in the simulation are summarized in Table 1. Below we describe the collected data, development of agent based simulation and validation of the agent based simulation.

\subsection{University database}

The flow of students through a university involved a modest number of decision points. Therefore, students were assigned specific daily activities, including both their routine course schedules and their activities during free time on campus. Students' course schedules were obtained from Concordia's undergraduate course database. To acquire data on student activities on campus during their free time, a questionnaire survey was conducted. A total of 260 questionnaires were collected from undergraduate engineering students at Concordia University. Students were asked to rank the frequency of their visits to places on campus (gym, library, laboratories, student lounge, other places on campus) and off campus visits from: never, sometimes, often and very often. Gym, library, laboratories and student lounge were chosen as the most frequently visited. Students were given the option to provide other choices in their response to questionnaires, however, they offered very few alternate locations which were not statistically significant compared to the main locations (only 2 out of 260 respondents suggested different location). These data were inputted into the simulation database to build student activity patterns. According to the collected data students were more likely to spend their free time on campus in the library, laboratories, student lounge and gym. Also some 
Fig. 1 Modeling structure

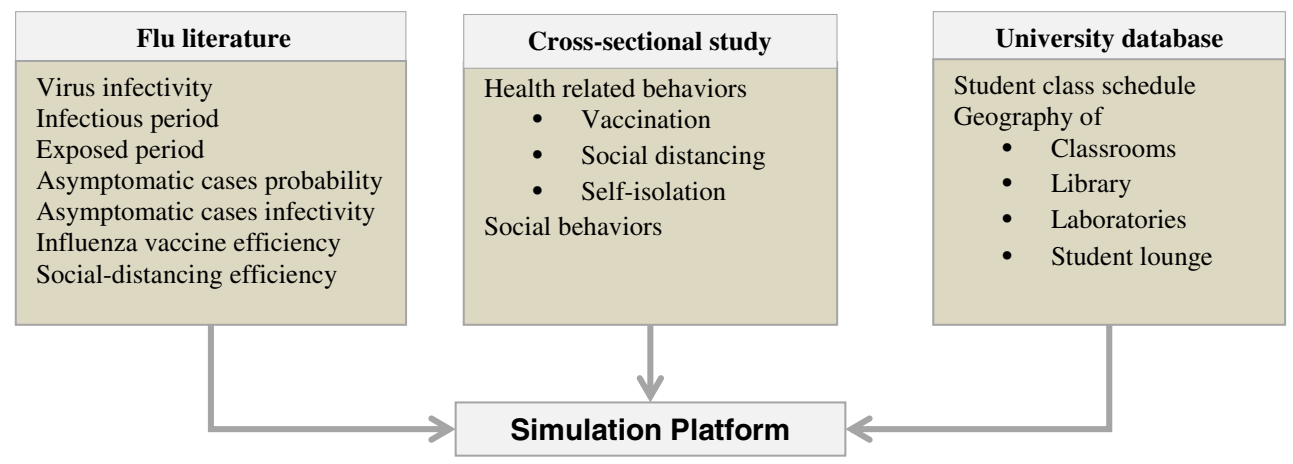

preferred to spend their free time off campus. In the simulation, whenever a 'student' finished a scheduled class, he/she was given the option to select the next location based on these activity patterns. The geography of each of these locations (including classrooms, library, laboratories and student lounge) were obtained from Concordia's security department and was incorporated into simulation to build the environment.

\subsection{Influenza parameters}

In this simulation once a susceptible person was exposed to the influenza virus, $s /$ he entered latent and incubation stages followed by a symptomatic or asymptomatic infectious period. During the latent period the individual was infected but not yet able to transmit the virus. The incubation period was considered to be one day longer than the latent period for influenza and was the period between the exposure to virus and the onset of symptoms of the disease. The duration of latent period is assumed to be 1 day with probability of 0.3 , 2 days with probability of 0.5 and 3 days with probability of 0.2 . for infectious- symptomatic period this distribution is 0.3 for 3 days of infection, 0.4 for 4 days of infection, 0.2 for 5 days of infection and 0.1 for 6 days of infection [18]. Each individual is assigned a health status attribute at a given time which is associated with one of those timelines. The probability of developing symptoms, given that the individual becomes infected, is 0.67 . We assume that an infected person who does not become ill is $50 \%$ less infectious than one who has, but the incubation and infectious period duration are the same as in those who exhibit symptoms [25].

\subsubsection{Influenza transmission}

One of the most crucial parameters that need to be quantified when simulating an infectious disease is the probability of virus transmission between any infectious and susceptible person. There are several modes of influenza transmission, and despite vast experimental and epidemiological literature on the matter, there is no conclusive assurance on the relative importance of those modes. Consequently, it is not possible to validate how transmission risk should be quantified [26]. In agent-based models such as ours, probability of the transmission of disease between two people in close contact over time is typically assumed to be captured with a hazard rate [26]. Although this hazard rate could vary according to factors such as temperature, humidity, ventilation, individual susceptibility, etc., we assume an average population hazard rate for influenza transmission [20]. These infectious contacts are believed to occur only within a specific radius of the infectious person [26]. The probability that a contact between a susceptible individual $(i)$ and an infectious one $(j)$ leads to exposure to the virus could be obtained using per minute hazard rates estimated by Haber et al. [20] for contacts between two $\operatorname{adults}(\lambda=0.00032)$. The probability that a susceptible individual becomes infected during interactions within a specific

Table 1 Disease Parameters

\begin{tabular}{llll}
\hline Disease parameter & Value & Reference & \\
\hline Latent period & Distribution specified in text & Elveback et al. & {$[18]$} \\
Infectious-symptomatic period & Distribution specified in text & Elveback et al. & {$[18]$} \\
P(Asymptomatic $\mid$ Infected) & 0.67 & Longini et al. & {$[25]$} \\
Hazard rate (per minute) & 0.00032 & Haber et al. & {$[20]$} \\
Specific radius for hazard rate & $1.88 \mathrm{~m}$ & Brankston et al. & {$[26]$} \\
Vaccine efficiency & $87 \%$ & Longini et al. & {$[22]$} \\
Social distancing efficiency & $50 \%$ & Mniszewski et al. & {$[24]$} \\
\hline
\end{tabular}


radius ( $1.888 \mathrm{~m}$ for influenza) could be calculated by transmission probability of per minute contact with any infectious individual that one comes into contact with:

$P($ infection $)=1-e^{-t}$

where $t$ is the duration of interaction. Since the number of people at a location at any time varies widely, once a susceptible person arrives in a location, $\mathrm{s} / \mathrm{he}$ might interact with more than one infectious person at a time. Therefore in this simulation once a susceptible person decided to leave a sub location in the model the probability of infection was calculated based on the period of contact for all the infectious interactions $\mathrm{s} / \mathrm{he}$ made in that sub location:

$P($ infection $)=1-e^{-\lambda\left(t_{2}+t_{2}+\ldots\right)}$

\subsection{Cross-sectional study}

We constructed an HBM based questionnaire to understand students' health related behaviors. To consider all the possible barriers and benefits that individuals might perceive for each intervention and possible perceptions about influenza which could be defined as their perceived severity and susceptibility, we included 2 to 3 questions for each factor. A 25-item questionnaire was developed to assess the study objectives. (Appendix I) The first part of the questionnaire contains 20 questions, separated into a five-point Likert scale ( $1=$ strongly disagree to $5=$ strongly agree) based on HBM factors (perceived susceptibility and severity toward influenza and the perceived benefits and barrier of its interventions). The second part of the questionnaire contains questions investigating students' history for applying the interventions, (3 items). (See Appendix I for more information). The survey was administered in two different sections of the same engineering course. The first section administered was a control and the second one involved a treatment consisting of a health promotion specialist talking to students about influenza and its interventions for $20 \mathrm{~min}$. The educational program focused on the core HBM variables: Susceptibility of people to the influenza virus, severity of influenza, benefits and barriers of vaccination, benefits and barriers of social distancing. A summary of the primary results of the questionnaire including descriptive statistics and multivariate logistic regression is illustrated in Appendix II. Data were analyzed using SPSS/PC software Version 13.0. Response categories for the 17 HBM questions were put into binary categories: either low (the five-point items between levels 1-2) or high (those between levels 35). "No interventions" were considered as the reference categories and p-values less than 0.05 were considered as statistically significant. Alpha coefficient was calculated as a measure of consistency for HBM variables assessed with more than one question. A multivariate logistic regression analysis was performed to identify significant predictors of the target preventive behaviors. Odds ratios (ORs) for each predictor were estimated from the logistic regression. Results of regression for the control indicate that all HBM variables but perceived severity of disease are significantly correlated with vaccination. Results of multivariate regression for the treatment group indicate that vaccination is highly correlated with all the HBM variables. Regression results for the control group indicate that all HBM variables are correlated with selfisolation, but the perceived benefit of self-isolation is not significant. Regression results for the treatment group indicate that perceived susceptibility, benefits and barriers are correlated with self-isolation, but the perceived benefit of selfisolation and perceived severity of influenza are not correlated. (Summary of the results are provided in Table 2 and more detailed information on the result of this cross sectional study is provided in Appendix II).

\subsubsection{Influenza intervention strategies and individual behavior}

According to Durham et al. in an agent-based model, particular protective health behavior of individuals could be incorporated into the simulation using the standard logistic regression equation which is expressed in term of odds ratio derived from the multivariate logistic regression analysis of HBM variables [17]. Therefore student protective behaviors (vaccination and social distancing) were estimated using the four core domains of the HBM: perceived susceptibility and perceived severity of influenza and perceived benefits and perceived barriers of the protective behavior. The probabilities of social distancing and vaccination for each individual incorporated into the simulation as the healthbehavior pattern were derived from the standard logistic regression equation expressed in terms of odds ratios. These odds ratios are provided in Table 2. (Further details are provided in Appendix II)

$p($ behavior $($ vaccination or social distancing $)) \frac{O R_{o}{ }^{*} \Pi_{i} O R_{i}^{X_{i}}}{1+O R_{o} * \Pi_{i} O R_{I}^{X_{i}}}$

To determine if an individual would engage in a specific behavior, a threshold value $(p(i))$ was generated in ARENA according to equation (3). If $p(i)>p$ (behavior), the individual "engages in behavior", otherwise, the individual "does not engage in behavior". $O R_{i}$ is the value of relative odds ratio which corresponds to the multivariate logistic regression. In equation (3), $x_{i}$ is a binary variable representing the state of the corresponding HBM domain, with a value of 1 indicating a 'high' state of the HBM domain and a value of 0 indicating a 
Table 2 Summary of HBM variables multivariable logistic regression odds ratio for influenza interventions

\begin{tabular}{|c|c|c|c|c|c|}
\hline Interventions & HBM variables & Odds ratio & Interventions & HBM variables & Odds ratio \\
\hline \multirow[t]{4}{*}{ Vaccination } & Perceived susceptibility & 2.6 & \multirow[t]{4}{*}{ Vaccination } & Perceived susceptibility & 3.41 \\
\hline & Perceived severity & NS & & Perceived severity & 1.73 \\
\hline & Perceived benefits & 2.58 & & Perceived benefits & NS \\
\hline & Perceived barriers & 0.421 & & Perceived barriers & 0.632 \\
\hline \multirow[t]{4}{*}{ Social- distancing } & Perceived susceptibility & 1.243 & \multirow[t]{4}{*}{ Social- distancing } & Perceived susceptibility & 1.541 \\
\hline & Perceived severity & NS & & Perceived severity & 2.623 \\
\hline & Perceived benefits & 2.564 & & Perceived benefits & 4.6 \\
\hline & Perceived barriers & 0.371 & & Perceived barriers & 0.762 \\
\hline
\end{tabular}

'low' state. Finally, $O R_{0}$ functions as a constant that defines the probability of the behavior when all $x_{i}$ variables are in their 'low' states [16]. For example for an individual in the control group with low perceived susceptibility $\left(x_{1}=0\right)$, high perceived severity $\left(x_{2}=1\right)$, high perceived benefit of vaccination $\left(x_{3}=1\right)$, high perceived barrier for vaccination $\left(x_{4}=1\right)$, the probability of vaccinating himself/herself against the flu is:

$p($ vaccination $)=\frac{0.35 \times\left(2.6^{0} \times 2.58^{1} \times 0.421^{1}\right)}{1+0.35 \times\left(2.6^{0} \times 2.58^{1} \times 0.421^{1}\right)}=0.47$

Note that since perceived severity is not a significant predictor of vaccination, it is not considered in the calculation of vaccination probability. Since we must calculate the probability of vaccination and social distancing for 4484 agents within our simulation, we calculate the probability of HBM variable combinations within both groups and expand it to all agents.

Longini et al. estimates the efficiency of vaccine to prevent infection to be $87 \%$ [22]. Those that were vaccinated and became infected had their infectiousness hazard rate reduced by a factor of $50 \%$, relative to unvaccinated cases. In addition, vaccination reduces the infectious period by one day [22]. Social distancing (avoidance of close physical contact) was employed in the model as a reduction in the probability of infection. Social distancing was assumed to reduce both the susceptibility and infectiousness of the population [24]. Self-isolation was employed in the model as an option for infectious people to go home as soon as the symptom of disease appear and stay there until they are recovered [10]. The rate of self-isolation is captured from the survey results.

\subsection{Simulation platform}

We created a virtual replication of an influenza outbreak in a university setting using an agent-based simulation. Simulation software Arena, version 14.0, by Rockwell
Automation was used. All experiments were conducted on a personal computer with 64 bit operating system, 3.40 GHz Intel Core i7-2600 CPU and 16.0 GB RAM. Below, details of the simulation model are discussed. The developed simulation model is based on campus geometry and classroom design, interaction between subjects (students in our case), and conditions for transferring virus. While physical configuration of the campus and the student dynamics are modeled based on extensive study of campus and subjects, virus spreading conditions are modeled as suggested in literature. The university was represented physically by a set of sublocations in which students were more likely to interact with each other. The locations were reasonably isolated from students of other majors. Each student moved from location to location throughout a typical day defined by his/her schedule. Each location in the simulation was described by a matrix of seating orders. Students were assigned to an element of the matrix randomly, upon their arrival to a location. For susceptible individuals, all the nearby elements which were within the attack radius were monitored for infectious contacts and once that person decided to leave the location the probability of infection were calculated. If infectious contacts were effective the health status was changed to exposed-noninfectious. Sub-locations (including, classrooms, laboratories, libraries and student lounge) in Arena were designed as stations. Each sub-location has its unique seating configuration and distances between seat-pairs are known. Let $S_{i}^{c}$ be the address of seat $i$ in station $c$. Consequently, the distance between seats $i$ and $j$ in a station is known, $d_{i j}^{c}$. Students walk between stations based on their schedules. Once they arrive at a station, they select a seat randomly. Some students may select isolated seats as a preventive strategy. Such behavior is replicated in the model based on the probabilities obtained from survey results. If students have free time between two consecutive classes, they are routed to various locations (cafeteria, library, gym etc.) based on their 
preferences (determined from the survey). Social interaction during off class hours were modeled based on the results obtained from the survey. Once agents leave the school, keeping track of their actions was not possible in the simulation. Hence the probability that transmission occurred during their absence was calculated for each susceptible person based on the average number of contacts made in their community or household, using the estimated duration of contacts and number of contacts in the household or community by a susceptible person with the age between 19-64, estimated by Haber et al. [20]. The overall architecture of the simulation model is illustrated in Fig. 2.

\subsubsection{Stations and influenza transmission in Arena model}

Stations are used to represent physical locations in the university campus such as classrooms, laboratories, library and the student-lounge. The distances between locations are incorporated in the model to simulate travelling times. Since each station has different characteristics, seating arrangements and capacity of stations are inserted in to the simulation model from an excel file. Due to their commonalities, we grouped locations (stations) in five sets: classrooms, library, other locations on-campus, off-campus locations and finally the students' homes. In Fig. 3, classrooms as 157 different stations in Arena simulation model is shown. Once students arrive to a station (e.g. a classroom), an available seat is randomly assigned and probability of infection is calculated based on the disease-state of agents sitting within the influenza attack distance and attack duration and hazard rate. The Arena simulation modules that are on the right of Fig. 3 are used to determine the seat allocation and infection probabilities. Similarly in Fig. 4, Arena simulation modules that represent the library and other on-campus locations that have a high impact on influenza spread are illustrated. Due to similarities between these physical locations, a single decision making process (Arena modules located right of Fig. 4) is used in the simulation model to determine the influenza spread.

In our study, an agent's interaction with others while he/she is off-campus is not modeled explicitly. Instead, the

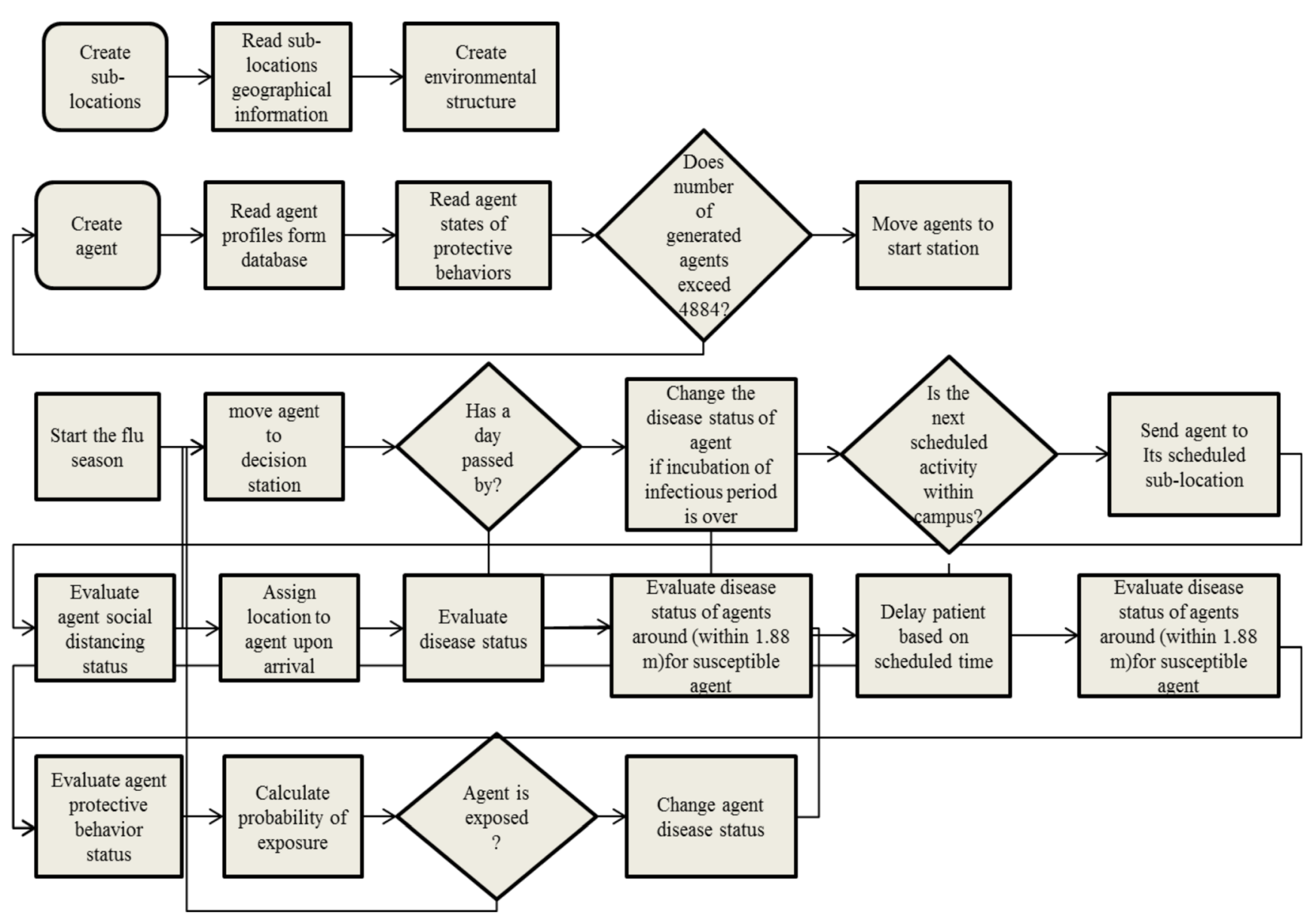

Fig. 2 Flow of agents within the simulation 
Classrooms: 157 different classrooms

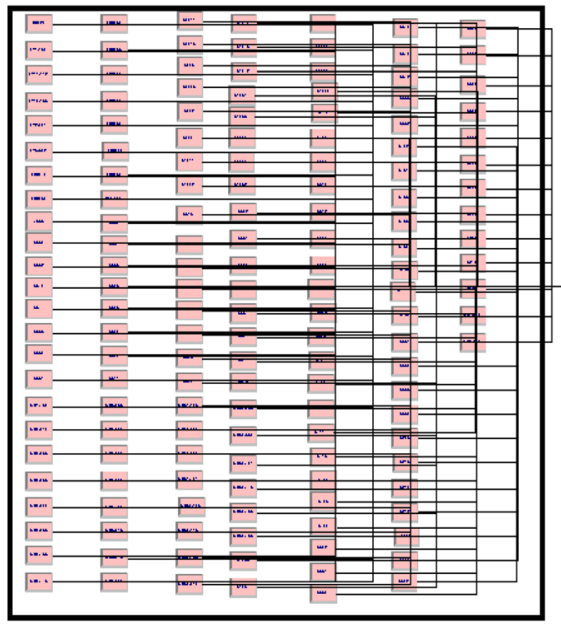

Determine seating positions and influenze transmision risk in classrooms

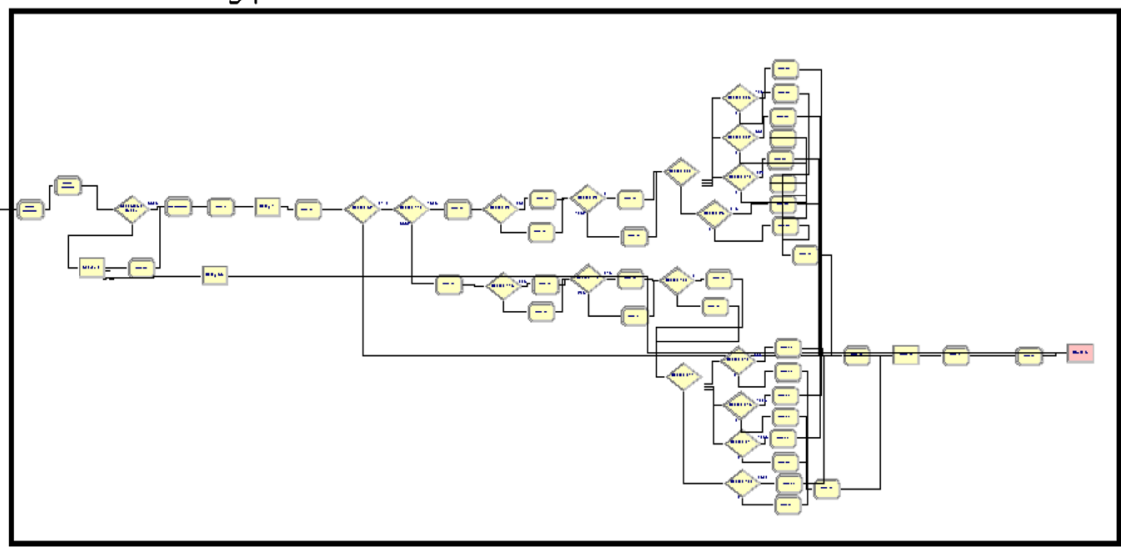

Fig. 3 Classrooms and influenza spread

probability of infection is computed according to the recommendations of current literature.

Finally, the home station is used to simulate the behavior of an agent at his/her home. In this station, disease state of agents is checked. If an agent is in latent or infectious state and the latent or infectious period is passed, disease state is changed to InfectiousAsymptomatic/Infectious-Symptomatic or Recovered, respectively. If the agent disease state is Susceptible the probability of infection is calculated. Figure 5 provides the Arena modules that are used to simulate the agent's behavior at his/her home.

\subsubsection{Agent routing: decision stations}

Decision stations are used to regulate agent flow in the simulation model. Once an agent finishes his/her activity, he/she enters a decision station to be routed to the next activity. If the

University Library: 63 possible destinations within the library

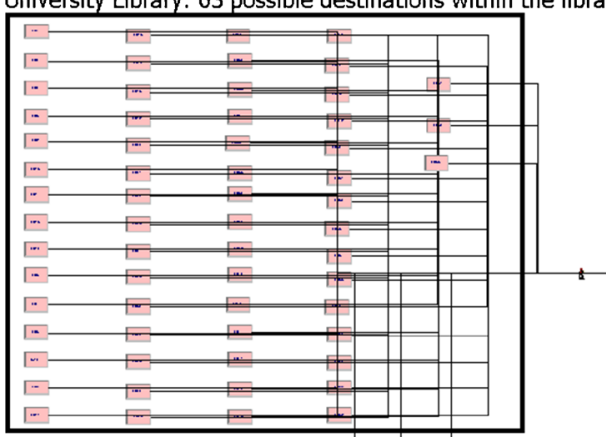

Determine seating configuration and study group interactions

Other Locations within the campus: 39 locations
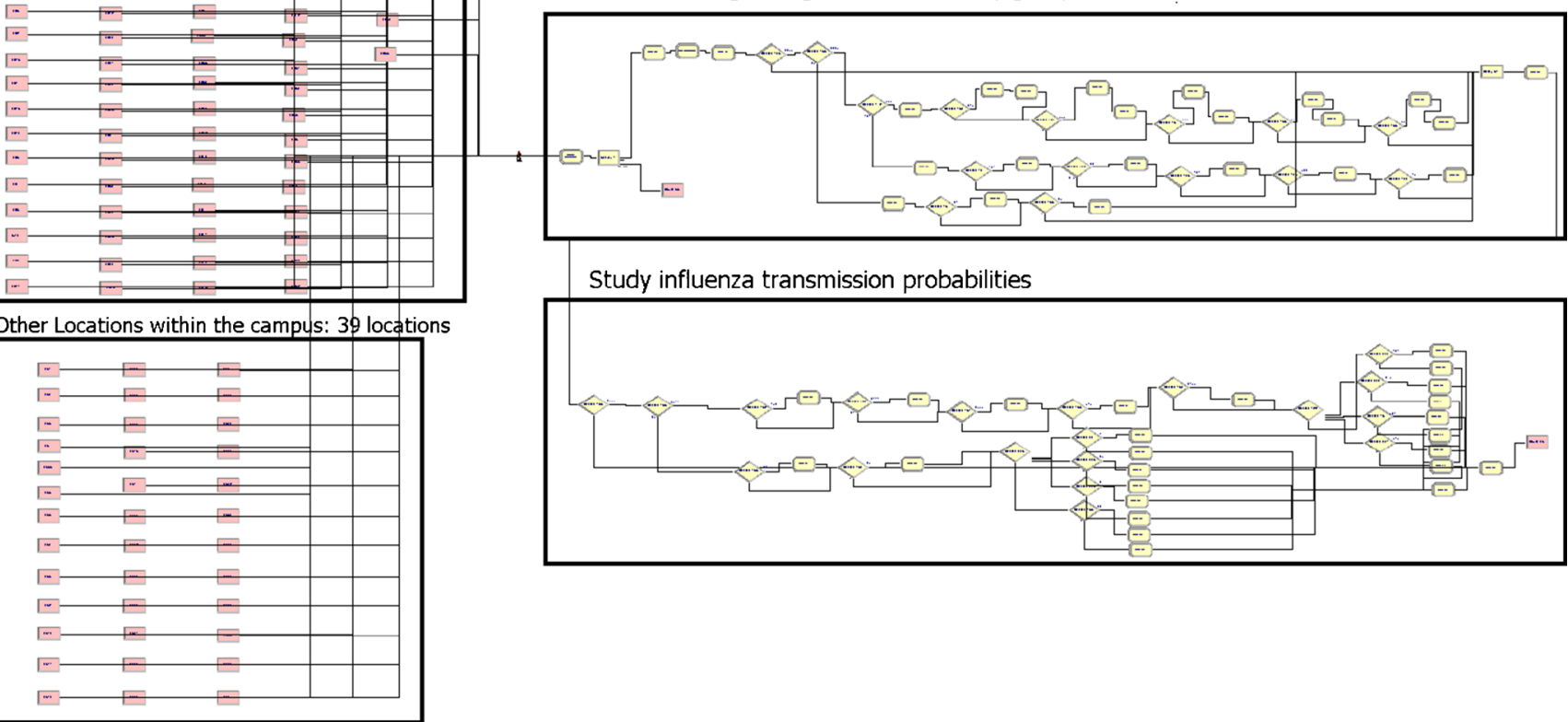

Study influenza transmission probabilities

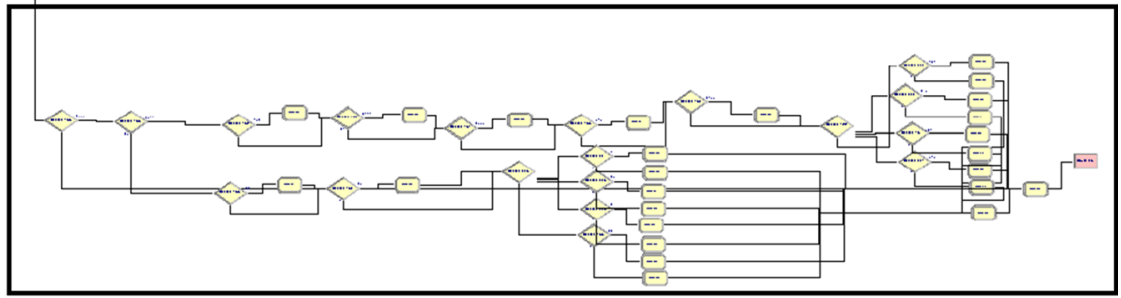

Fig. 4 Library and other on-campus locations and influenza spread 


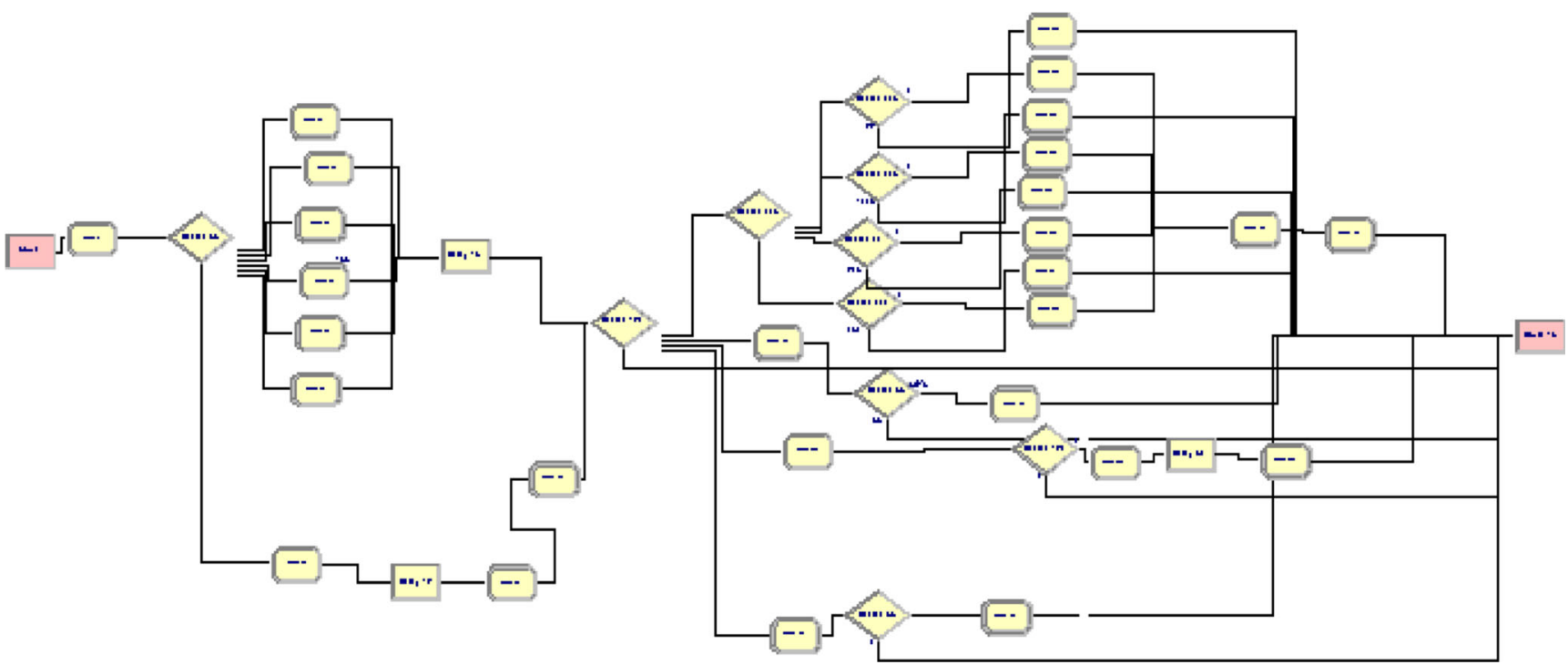

Fig. 5 Home stations

next activity is a scheduled class starting within $20 \mathrm{~min}$, the agent is held in the decision station until the activity starts. If the agent has more than $20 \mathrm{~min}$ to start his/her next activity, then the agent is routed to one of the following stations: library, laboratory, student lounge, home or off- -campus, based on the probabilities captured from the survey. Figure 6 provides the Arena modules used for determining agent's next event.

\subsection{Model validation}

Validation of agent based epidemiological models is notoriously difficult [8]. Reliable data sources on influenza transmission that could provide strong evidence for the accuracy of simulation results are scarce. Therefore transmission models are generally validated by comparing simulation results with similar agent based simulations. Consistent with previous agent-based simulations, a baseline scenario is modeled and the results are compared with that of similar studies. The baseline scenario was defined without consideration of individual protective behaviors. As in Longini et al. we assume that $33 \%$ of individuals who became infected withdrew from their daily activity schedules once they became ill, and remained at home through their symptomatic period. This assumption is based on an estimate of the probability of severe cases of influenza within the population [22]. Two approaches have been considered to validate the proposed simulation model: i) duration to reach peak infection ratio; ii) $R_{0}$.

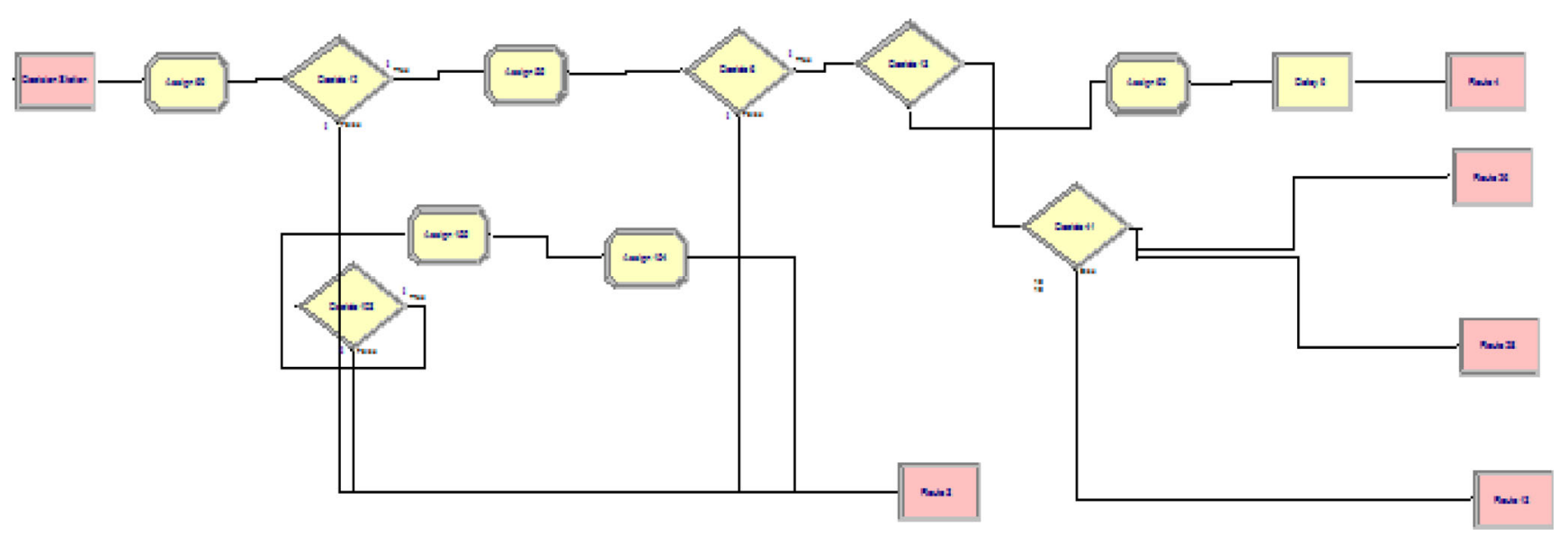

Fig. 6 Determine agent's next event in Arena 
First, the peak period of the outbreak was obtained from the smoothed number of infected individuals per day in the system with the baseline scenario of 4864 susceptible students. The number of infections and the attack rates of influenza with $95 \%$ confidence intervals for the baseline scenario from 20 simulations are shown in Table 3. The peak infection rate occurred from days 24 to 30 after the start of the outbreak with the average rate of 165 new cases per day (Fig. 7). By the day when the peak new case rate occurs, the cumulative number of infections reaches the average of 1813.6. The simulation was conducted through day 60 , by which time an average of 2735 people had been infected and the overall attack rate was $55 \%$ (in a population with 4884 susceptible individuals and no protective behaviors). These results were consistent with the study of Yang and Atkinson (2004) in a characteristically similar population with the peak time between 20 and 25 days and overall attack rate of $50.6 \%$ [8].

Second, we validate the model by deriving the value for $\mathrm{R}_{0}$, the number of secondary infections of individuals in a susceptible population resulting from the introduction of a single infectious individual. Traditionally $\mathrm{R}_{0}$ was estimated from event-based mathematical (Susceptible-Infected-Recovered) models. Values of $\mathrm{R}_{0}$ from these traditional models of influenza vary from 0.9 to 2.1 with a mean of 1.3 [27-30]. The approach for validating agent-based models such as ours was developed by Longini et al. This method calculates the number of secondary infections after entering only one infected individual in the simulation [22]. Longini et al. estimates the value of $\mathrm{R}_{0}$ to be 1.68 [22]. In our simulation we took the same approach and entered one infected individual to system. The value of $R_{0}$ after 20 simulations was estimated to be 1.45 . This value is also consistent with that of Yang and Atikson's agent-based simulation and that of Mao [8, 31].

\section{Experiments and results}

In this section, we present two experiments (control and treatment) that we designed and analyzed through the agent- based simulation and discuss the numerical results of our analysis. In the first experiment, we use the result of multivariate logistic regression of the HBM study for the control group. The probabilities of developing self-initiated behaviors (vaccination and social distancing) obtained from HBM study are incorporated into the simulation. In the second experiment, we again use the result of HBM multivariate logistic regression to incorporate the probabilities of developing such behaviors for treatment group that were the subject of an educational program on influenza and its interventions. To obtain insight into the model, we analyze the results of these experiments through influenza outbreak characteristics (such as total number of infection, infection rate, peak period of outbreak and rate of new cases in the peak period) and individual characteristics (such as total number of individuals who developed both behaviors, total number of individuals who just applied one behaviors, rate of infection for individuals who developed the behaviors).

\subsection{Health-related protective behaviors (control group)}

The first scenario included the HBM variables, which were used to calculate the probability of developing the protective behaviors (social distancing and vaccination) for each agent in the system and also the probability of self-isolation based on the result of cross sectional study for the control group. It should be noted that individuals who applied social distancing in their contacts with others when they were sick reduced the probability of infection for others. An average of $1614 \pm 11$ cases of influenza was observed with the attack rate of approximately $34 \%$. We run the simulations for 70 days, which is the average duration of a typical influenza season. The peak of the outbreak was also delayed by an average of 6 days and the average rate of new cases in the peak period was 123 per day. Of the average of $488 \pm 9$ people who developed both protective behaviors only $18 \pm 3$ did not escape infection. Of $603 \pm 8$ individuals who just vaccinated themselves against influenza $62 \pm 3$ got sick with flu and from $628 \pm 11$ students who

Table 3 Summary of simulation results

\begin{tabular}{|c|c|c|c|c|c|c|}
\hline \multirow[t]{2}{*}{ Statistics } & \multirow{2}{*}{$\begin{array}{l}\text { Baseline scenario } \\
\text { (no protective behavior) } \\
\mathrm{N}\end{array}$} & \multirow{2}{*}{$\begin{array}{l}\text { Control group } \\
95 \% \mathrm{CI}\end{array}$} & \multicolumn{4}{|c|}{ Treatment group } \\
\hline & & & $\mathrm{N}$ & $95 \% \mathrm{CI}$ & $\mathrm{N}$ & $95 \% \mathrm{CI}$ \\
\hline Total Cases & 2735.17 & \pm 31.61 & 1614.61 & \pm 11.34 & 987.12 & \pm 16.35 \\
\hline Peak Cases & 165.44 & & 123.31 & & 87.5 & \\
\hline Peak Day & $20-25$ & & $26-34$ & & $37-45$ & \\
\hline Self-Isolation Cases & 896.31 & \pm 17.81 & 483.41 & \pm 9.21 & 383.41 & \pm 11.34 \\
\hline
\end{tabular}


Fig. 7 Number of new infections per day

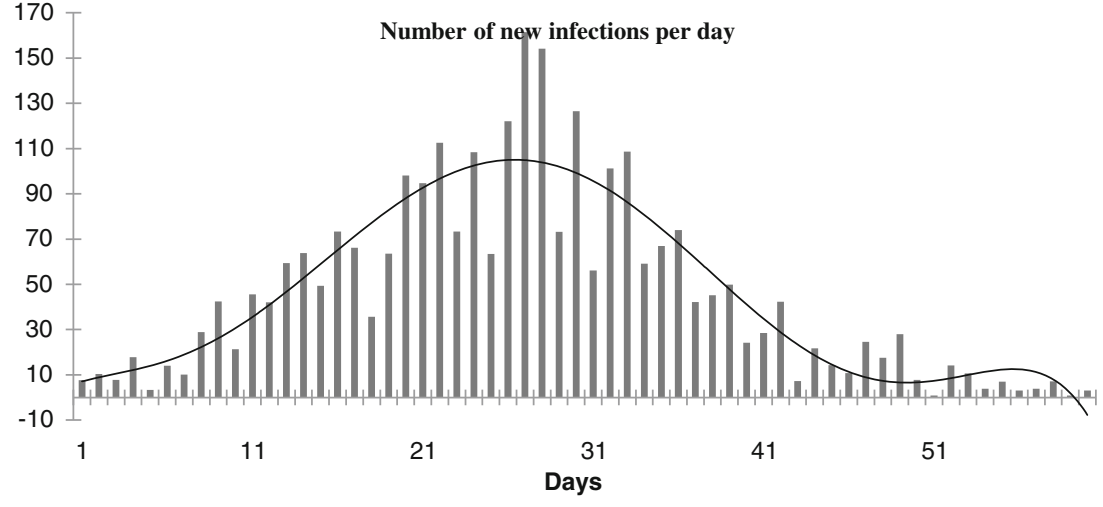

just applied social distancing on their contacts with others $289 \pm 3$ still got sick with flu. The self-initiated protective behaviors of the population toward influenza were able to reduce the attack rate by more than $16 \%$. $483 \pm 6$ people preferred to stay at home when they were sick with flu. The difference between the protection efficiency of vaccination and social distancing explains the significant difference between the rate of people who got infected even though they were vaccinated and those who applied social distancing in their contacts. A total of 1721 (approximately $35 \%$ ) students developed at least one self-initiated protective behavior toward influenza. Therefore an average of $75 \%$ percent of people who got sick during flu season were the people with no self-initiated protective behavior toward influenza. These results illustrate that considering the current state of individuals perceived susceptibility and severity of influenza along with the perceived benefits and perceived barriers of interventions could have a significant effect on the attack rate of influenza. (Table 4)

\subsection{Educational program (treatment group)}

The second scenario includes the protective behaviors that individuals developed after receiving a treatment in the form of an educational program designed to increase students' willingness to get vaccinated or apply social distancing in their social contacts with others in case of an influenza outbreak in the university. The multivariable logistic regression of HBM variables provided us with individual health-related activities during a flu season. From 20 simulation runs for this scenario, the result illustrates that only an average of $987 \pm 6$ (attack rate of $21 \%$ ), cases of influenza occurred. Of the 598 \pm 12 people (on average) who developed both protective behaviors only $21 \pm 5$ did not escape the infection. Of the $1013 \pm 22$ whom just vaccinated themselves against influenza $95 \pm 4$ were sick with flu and from $928 \pm 16$ students who just applied social distancing on their contacts with others, only $273 \pm 9$ were sick with flu. $283 \pm 6$ people preferred to stay at home when they were sick with flu. The total attack rate of influenza decreased by approximately $12 \%$ after the educational program, which was the result of a $20 \%$ increase in the number of vaccinations and a $42 \%$ increase in developing social distancing by students. The peak of the outbreak was shifted by an average of 8 days and the total number of new infected cases in the peak of the outbreak decreased by $34 \%$. The summary of results extracted from simulations for both scenarios is described in Table 4.
Table 4 Comparisons of control and treatment scenarios

\begin{tabular}{lllll}
\hline Statistics & Control group & \multicolumn{4}{l}{ Treatment group } \\
\cline { 3 - 5 } & $\mathrm{N}$ & $95 \%$ CI & $\mathrm{N}$ & $95 \%$ CI \\
\hline Total number of hybrid behaviors & 488 & \pm 9 & 598 & \pm 12 \\
Total infected cases with hybrid behaviors & 18 & \pm 4 & 21 & \pm 5 \\
Total number of vaccination & 603 & \pm 8 & 1013 & \pm 22 \\
Total infected cases for vaccination & 62 & \pm 3 & 95 & \pm 4 \\
Total number of social distancing & 628 & \pm 11 & 928 & \pm 16 \\
Total number of infected cases with social distancing & 289 & \pm 7 & 273 & \pm 9
\end{tabular}




\subsection{Discussion of results}

The agent-based simulation model presented in this paper is the first of its kind to incorporate the effect of instinctive protective behaviors that individuals develop on the spread of an infectious disease within a structured population. The evaluation of results indicate that such behaviors were successful in controlling the outbreak within a high contact rate place such as a university, with a large decrease on the attack rate (approximately $17 \%$ ) of disease among the population and a reduction in peak outbreak level of $25 \%$. This result highlights the importance of considering self-initiated behaviors that individuals develop to protect themselves in case of an outbreak. It should be noted that both protective behaviors (social distancing and vaccination) are dependent on each other, which may explain the enhancing effect of these behaviors on controlling the outbreak, compared to other studies which have incorporated influenza interventions as independent parameters into their simulation [20-22]. Characteristics of influenza virus transmission as an airborne virus explains the effect of social distancing on controlling the transmission since individuals have to be within a certain distance of each other for a contact to be effective. The output of our simulations also provide evidence that, along with vaccination, non-pharmaceutical interventions such as social distancing are able to control the outbreak of disease, which could help individuals with perceived high barriers of vaccination to protect themselves against influenza. The simulation also provides significant evidence for the effect of an HBM theorybased educational program to increase the rate of applying the target interventions among populations (vaccination by $22 \%$ percent and social distancing by $41 \%$ ) and consequently to control the outbreak. Although the probability that a person develops a protective behavior cannot be entirely controlled, studies have demonstrated that providing information which targets different aspects of disease and its interventions could have a significant effect on such probabilities [7]. For example, our study in Concordia University illustrates the positive correlation between providing students information on influenza and its interventions and developing protective behaviors.

The modeling approach used to simulate the transmission of influenza provides a novel representation of the real world by considering aspects of both social and health related individual behavior patterns, which could be applied to different circumstances of other infectious diseases or other population structures. Although a university environment was defined as the target population in this simulation, the model could be applied to larger case studies, provided sufficient data resources for both individual activity patterns and health behaviors (by conducting HBM on populations with more characteristics diversity such as age, race and education level). Despite the advantages of this study such as understanding individual behavior and its effect on the spread of disease along with the efficiency of educational programs to shape behavior; some of the characteristics of this model such as the massive data collection required to develop the social activity patterns, the uncertainty of influenza transmission probability calculation and the limitations of HBM to explore other factors that might influence decision making such as fear and population diversity, could lessen the efficiency of this simulation on larger case studies. Instead, lessons learned from models at this scale may need to be generalized for larger populations.

\section{Conclusions}

This paper demonstrates how agent based simulation can be utilized to study influenza outbreak and assess various prevention strategies. A case study among engineering students at a university campus was considered. The results show that the impact of vaccination and education on influenza prevention can accurately be studied using simulation. Using such tools, policymakers can plan the distribution of limited funds on various prevention strategies to optimize cost and public health. Through design of experiments, contributions of individual interactive prevention strategies on influenza prevention can be estimated and trend-lines can be derived. Finally, the case study can be expanded to study other social systems such as corporations, hospitals and even entire cities. Our results also show that educational programs and information distribution could be very helpful in changing individual attitudes and beliefs toward influenza, which could in turn lead to developing protective behaviors. In addition, we expect to see benefits from policies aimed at reducing the costs of vaccination and increasing accessibility in places such as university-based health centers. Moreover, policies to minimize the costs and consequences of missing work and school in order to support selfisolation during outbreaks may be a key to reducing the seasonal influenza outbreaks. 
Appendix I: Questionnaire

\section{Gender \\ O Female O Male}

Status

O Undergraduate Student $\bigcirc$ Graduate Student $\bigcirc$ Faculty $\bigcirc$ Staff $\bigcirc$ Other

Faculty

O ENCS O JMSB O Fine Arts $\bigcirc$ Arts \& Science $\bigcirc$ Other

\begin{tabular}{|c|c|c|c|c|c|}
\hline & Strongly Disagree & Disagree & Neutral & Agree & $\begin{array}{c}\text { Strongly } \\
\text { Agree }\end{array}$ \\
\hline If I get the influenza virus, I will get sick. & 0 & 0 & 0 & 0 & 0 \\
\hline $\begin{array}{l}\text { If I get the influenza virus, it will disrupt my } \\
\text { studies. }\end{array}$ & O & 0 & 0 & 0 & 0 \\
\hline $\begin{array}{l}\text { If I get the influenza virus, others in my home } \\
\text { will get sick. }\end{array}$ & O & O & O & O & O \\
\hline $\begin{array}{l}\text { I am at risk of getting the influenza virus by } \\
\text { going to the university. }\end{array}$ & O & O & 0 & 0 & 0 \\
\hline $\begin{array}{l}\text { My family members are at risk of getting the } \\
\text { influenza virus. }\end{array}$ & O & O & O & O & O \\
\hline $\begin{array}{l}\text { I feel knowledgeable about my risk of getting the } \\
\text { influenza virus. }\end{array}$ & O & 0 & 0 & O & O \\
\hline $\begin{array}{l}\text { If I get the influenza vaccine, I will not get sick } \\
\text { from the influenza virus. }\end{array}$ & O & O & O & O & O \\
\hline $\begin{array}{l}\text { If I get the influenza vaccine, I will have side } \\
\text { effects. }\end{array}$ & 0 & 0 & 0 & 0 & 0 \\
\hline It is inconvenient to get the influenza vaccine. & 0 & 0 & 0 & 0 & 0 \\
\hline $\begin{array}{l}\text { I will recover faster if I rest at home as soon as } \\
\text { influenza symptoms develop. }\end{array}$ & 0 & 0 & 0 & 0 & 0 \\
\hline $\begin{array}{l}\text { Staying at home when I am sick has a negative } \\
\text { effect on my studies. }\end{array}$ & O & O & O & O & O \\
\hline $\begin{array}{l}\text { My professors do not consider illness as an } \\
\text { excusable reason for absence. }\end{array}$ & O & O & 0 & O & O \\
\hline $\begin{array}{l}\text { Avoiding crowded places reduces my likelihood } \\
\text { of catching influenza. }\end{array}$ & O & O & O & O & O \\
\hline $\begin{array}{l}\text { Avoiding physical contact with sick people } \\
\text { reduces my likelihood of catching influenza. }\end{array}$ & O & O & O & O & O \\
\hline $\begin{array}{l}\text { It is difficult to avoid close physical contact with } \\
\text { my friends when I am sick. }\end{array}$ & O & O & O & O & O \\
\hline $\begin{array}{l}\text { It is difficult to avoid crowded places at the } \\
\text { university. }\end{array}$ & 0 & 0 & 0 & O & 0 \\
\hline $\begin{array}{l}\text { My knowledge about influenza and its } \\
\text { interventions is sufficient. }\end{array}$ & O & O & O & O & O \\
\hline I will use medication if I get the influenza virus. & 0 & O & O & O & O \\
\hline \multicolumn{6}{|c|}{ Where do you prefer to spend time when you have a gap between lectures? } \\
\hline & Never & Sometimes & Often & \\
\hline Off Campus & O & O & O & \multicolumn{2}{|c|}{0} \\
\hline Le Gym & O & 0 & O & \multicolumn{2}{|r|}{0} \\
\hline Library & O & \multirow{2}{*}{$\begin{array}{l}0 \\
0\end{array}$} & O & \multicolumn{2}{|r|}{0} \\
\hline Laboratories & O & & 0 & \multicolumn{2}{|r|}{ O } \\
\hline Student Lounge in Hall Building & O & O & O & \multicolumn{2}{|r|}{ O } \\
\hline Other (Please specify): & 0 & 0 & O & \multicolumn{2}{|r|}{0} \\
\hline
\end{tabular}


How often do the following resources provide you with information about influenza?

\begin{tabular}{|c|c|c|c|c|}
\hline & Never & Sometimes & Often & $\begin{array}{l}\text { Very } \\
\text { Often }\end{array}$ \\
\hline TV & 0 & 0 & 0 & 0 \\
\hline Newspaper & 0 & 0 & 0 & 0 \\
\hline Family member or friend & 0 & 0 & 0 & 0 \\
\hline Pharmacist & 0 & 0 & 0 & 0 \\
\hline Nurse & 0 & 0 & 0 & 0 \\
\hline Posters around university & 0 & 0 & 0 & 0 \\
\hline Internet & O & O & O & O \\
\hline Other (Please specify): & 0 & O & O & O \\
\hline \multicolumn{5}{|c|}{ How likely are you to use the following to prevent influenza? } \\
\hline & Very Unlikely & Unlikely & Likely & $\begin{array}{l}\text { Very } \\
\text { Likely }\end{array}$ \\
\hline Vaccine & 0 & 0 & 0 & 0 \\
\hline Avoiding physical contact & O & O & O & O \\
\hline Using masks & O & O & O & O \\
\hline Using hand sanitizer & O & O & O & O \\
\hline Antiviral drugs & O & O & O & O \\
\hline Other (Please specify): & 0 & O & O & 0 \\
\hline
\end{tabular}

Have you been vaccinated against influenza this year?

O Yes O No

Have you ever been vaccinated against influenza?

O Yes O No

Does someone with a compromised immune system live in your home (e.g., infants, elderly, pregnant women)? $\mathrm{O}$ Yes O No 


\section{Appendix II: Survey results}

Table 5 Summary of Health Belief Model responses of survey participants

\begin{tabular}{|c|c|c|c|c|}
\hline \multirow{2}{*}{$\begin{array}{l}\text { Items } \\
\text { HBM variables }\end{array}$} & \multicolumn{2}{|c|}{ Control group $(n=120)$} & \multicolumn{2}{|c|}{ Treatment group $(n=140)$} \\
\hline & Mean(SD) & Alpha & Mean(SD) & Alpha \\
\hline $\begin{array}{l}\text { Perceived Susceptibility: } \\
\text { If I get the influenza virus, I will get sick. } \\
\text { I am at risk of getting the influenza virus by going to the university. } \\
\text { My family members are at risk of getting the influenza virus. }\end{array}$ & $3.07(0.76)$ & 0.67 & $3.87(0.82)^{*}$ & 0.72 \\
\hline $\begin{array}{l}\text { Perceived Severity } \\
\text { If I get the influenza virus, it will disrupt my studies. } \\
\text { If I get the influenza virus, others in my home will get sick. }\end{array}$ & $3.02(0.79)$ & 0.61 & $3.12(0.89)$ & 0.59 \\
\hline $\begin{array}{l}\text { Vaccination Perceived Benefits } \\
\text { If I get the influenza vaccine, I will not get sick from the influenza virus. }\end{array}$ & $3.05(0.72)$ & & $3.16(0.63)$ & \\
\hline $\begin{array}{l}\text { Vaccination Perceived Barriers } \\
\text { If I get the influenza vaccine, I will have side effects. }\end{array}$ & $3.87(0.8)$ & 0.63 & $2.33(0.88)^{* *}$ & 0.57 \\
\hline $\begin{array}{l}\text { Self- Isolation Perceived Benefits } \\
\text { I will recover faster if I rest at home as soon as influenza symptoms develop. }\end{array}$ & $3.72(0.92)$ & & $3.78(0.93)$ & \\
\hline $\begin{array}{l}\text { Self- Isolation Perceived Barriers } \\
\text { Staying at home when I am sick has a negative effect on my studies. } \\
\text { My professors do not consider illness as an excusable reason for absence. }\end{array}$ & $3.97(0.85)$ & 0.83 & $3.51(0.62)$ & 0.71 \\
\hline $\begin{array}{l}\text { Physical Distancing Perceived Benefit } \\
\text { Avoiding crowded places reduces my likelihood of catching influenza. } \\
\text { Avoiding physical contact with sick people reduces my likelihood of catching influenza }\end{array}$ & $3.51(0.78)$ & 0.69 & $4.23(0.89)^{*}$ & 0.61 \\
\hline $\begin{array}{l}\text { Physical Distancing Perceived Barriers } \\
\text { It is difficult to avoid close physical contact with my friends when I am sick. } \\
\text { It is difficult to avoid crowded places at the university. }\end{array}$ & $3.72(0.79)$ & 0.73 & $3.78(1.12)$ & 0.54 \\
\hline
\end{tabular}

All above questions are scaled from 1 to 5: strongly disagree, disagree, neutral, agree and strongly agree

The significance of differences between answers of control and treatment group are indicated: * for $p \leq 0.05$; ** for $p \leq 0.01$

Table 6 Multivariate logistic regression of HBM variables attitudinal variables associated with influenza interventions

\begin{tabular}{|c|c|c|c|c|c|c|c|c|}
\hline & \multicolumn{4}{|l|}{ Vaccination } & \multicolumn{4}{|c|}{ Physical Distancing } \\
\hline & \multicolumn{2}{|c|}{ Control group } & \multicolumn{2}{|c|}{ Treatment group } & \multicolumn{2}{|c|}{ Control group } & \multicolumn{2}{|c|}{ Treatment group } \\
\hline & Odds ratio & $P$-value & Odds ratio & $P$ - Value & Odds ratio & $P$-value & Odds ratio & $P$-value \\
\hline \multicolumn{9}{|l|}{ Perceived Susceptibility } \\
\hline strongly agree, agree and neutral & 1 & & 1 & & 1 & & 1 & \\
\hline strongly disagree and disagree & 2.6 & $0.003 * *$ & 3.41 & $0.041^{*}$ & 1.243 & $0.032 *$ & 1.541 & $0.0118 *$ \\
\hline \multicolumn{9}{|l|}{ Perceived Severity } \\
\hline strongly agree, agree and neutral & 1 & & 1 & & 1 & & 1 & \\
\hline strongly disagree and disagree & 1.42 & 0.58 & 1.73 & $0.0032 * *$ & 1.426 & 0.0566 & 2.623 & $0.015^{*}$ \\
\hline \multicolumn{9}{|l|}{ Vaccination Perceived Benefits } \\
\hline strongly agree, agree and neutral & 1 & & 1 & & NA & NA & NA & NA \\
\hline strongly disagree and disagree & 2.58 & $0.0061^{* *}$ & 2.62 & 0.086 & NA & NA & NA & NA \\
\hline \multicolumn{9}{|l|}{ Vaccination Perceived Barriers } \\
\hline strongly agree, agree and neutral & 1 & & 1 & & NA & NA & NA & NA \\
\hline strongly disagree and disagree & 0.421 & $0.012 *$ & 0.632 & $0.021 *$ & NA & NA & NA & NA \\
\hline \multicolumn{9}{|l|}{ Physical Distancing Perceived Benefit } \\
\hline strongly agree, agree and neutral & NA & NA & NA & NA & 1 & & 1 & \\
\hline strongly disagree and disagree & NA & NA & NA & NA & 2.564 & $0.041^{*}$ & 4.6 & $0.0056^{* *}$ \\
\hline \multicolumn{9}{|l|}{ Physical Distancing Perceived Barriers } \\
\hline strongly agree, agree and neutral & NA & NA & NA & NA & 1 & & 1 & \\
\hline strongly disagree and disagree & NA & NA & NA & NA & 0.371 & $0.026^{*}$ & 0.762 & $0.0036^{* *}$ \\
\hline
\end{tabular}

$* p \leq 0.05 ; * * \leq \leq 0.01 ; * * * \leq 0.001 ;$ NA (Not Applicable) 


\section{References}

1. Bell DM (2006) Non-pharmaceutical interventions for pandemic influenza, international measures. Emerging infectious diseases 12(1):81-87

2. Molinari NA, Ortega-Sanchez IR, Messonnier ML, Thompson WW, Wortley PM, Weintraub E, Bridges CB (2007) The annual impact of seasonal influenza in the US: measuring disease burden and costs. Vaccine 25(27):5086-5096

3. Thompson WW, Shay DK, Weintraub E, Brammer L, Bridges CB, Cox NJ, Fukuda K (2004) Influenza-associated hospitalizations in the United States. the journal of the. American Medical Association 292(11):1333-1340

4. Thompson WW, Shay DK, Weintraub E, Brammer L, Cox N, Anderson LJ, Fukuda K (2003) Mortality associated with influenza and respiratory syncytial virus in the United States. The journal of the American Medical Association 289(2):179-186

5. Heymann A, Chodick G, Reichman B, Kokia E, Laufer J (2004) Influence of school closure on the incidence of viral respiratory diseases among children and on health care utilization. The Pediatric Infectious Disease Journal 675-677

6. Barry, J. (2005). The great influenza: The story of the deadliest pandemic in history. Penguin

7. Durham DP, Casman EA (2012) Incorporating individual health-protective decisions into disease transmission models: a mathematical framework. Journal of The Royal Society Interface 9(68):562-570

8. Yang Y, Atkinson P (2008) Individual space-time activity-based model: a model forthe simulation of airborne infectious-disease transmission by activity-bundle simulation. Environment and Planning B, Planning and Design, pp 80-99

9. Dalton CB, Durrheim DN, Conroy MA (2008) Likely impact of school and childcare closures on public health workforce during an influenza pandemic: a survey. Commun Dis Intell 32(2):261-262

10. King JC Jr, Stoddard JJ, Gaglani MJ, Moore KA, Magder L, McClure E, Neuzil K (2006) Effectiveness of school-based influenza vaccination. New England Journal of Medicine 355(24):2523-2532

11. Hilyer, B., Veasey, A., Oldfield, K., \& Craft-McCormick, L. (1999). Effective safety and health training. CRC Press

12. Janz NK, Becker MH (1984) The health belief model: A decade later. Health Education \& Behavior 11(1):1-47

13. Coe AB, Gatewood SB, Moczygemba LR (2012) The use of the health belief model to assess predictors of intent to receive the novel (2009) H1N1 influenza vaccine. Innovations in pharmacy 3(2):1

14. Lau J, Nelson TF, Yeunga CY, Choia KC, Chenga Mabel YM, Tsuia G (2010) Factors in association with acceptability of A/H1N1 vaccination during the influenza $\mathrm{A} / \mathrm{H} 1 \mathrm{~N} 1$ pandemic phase in the Hong Kong general population. Vaccine 28:4632-4637

15. Maurer J, Uscher-Pines L, Harris KM (2010) Awareness of government seasonal and $2009 \mathrm{H} 1 \mathrm{~N} 1$ influenza vaccination recommendations among targeted US adults: The role of provider interactions. American journal of infection control 38(6):489-490
16. Painter JE et al (2010) Development, theoretical framework, and lessons learned from implementation of a school-based influenza vaccination intervention. Health promotion practice 11.3(suppl): $42 \mathrm{~S}-52 \mathrm{~S}$

17. Durham DP, Casman EA, Albert SM (2012) Deriving behavior model parameters from survey data: self-protective behavior adoption during the 2009-2010 influenza a (H1N1) pandemic. Risk Analysis 32(12):2020-2031

18. Elveback LR, Fox JP, Ackerman E, Langworthy A, Boyd M, Gatewood L (1976) An influenza simulation model for immunization studies. American Journal of Epidemiology 103(2):152-165

19. Halloran ME, Ferguson NM, Eubank S, Longini IM (2008) Modeling targeted layered containment of an influenza pandemic in the United States. PNAS 105-12:4639-44

20. Haber MJ, Shay DK, Davis XM, Patel R, Jin X, Weintraub E, Thompson WW (2007) Effectiveness of interventions to reduce contact rates during a simulated influenza pandemic. Emerging infectious diseases 13(4):581

21. Das TK, Savachkin AA, Zhu Y (2008) A large-scale simulation model of pandemic influenza outbreaks for development of dynamic mitigation strategies. IIE Transactions 40(9):893-905

22. Longini IM, Halloran ME, Nizam A, Yang Y (2004) Containing pandemic influenza with antiviral agents. American journal of epidemiology 159(7):623-633

23. Lee BY, Brown ST, Cooley P, Potter MA, Wheaton WD, Voorhees RE, Burke DS (2010) Simulating school closure strategies to mitigate an influenza epidemic. Journal of public health management and practice : JPHMP 16(3):252

24. Mniszewski SM, Del Valle SY, Stroud PD, Riese JM, Sydoriak SJ (2008) Pandemic simulation of antivirals + school closures: buying time until strain-specific vaccine is available. Computational and Mathematical Organization Theory 14(3): 209-221

25. Longini IM, Nizam A, Xu S, Ungchusak K, Hanshaoworakul W, Cummings DA, Halloran ME (2005) Containing pandemic influenza at the source. Science 309(5737):1083-1087

26. Brankston G, Gitterman L, Hirji Z, Lemieux C, Gardam M (2007) Transmission of influenza $\mathrm{A}$ in human beings. Lancet Infectious Diseases 257-65

27. Diekmann OH (1990) On the definition and the computation of the basic reproduction ratio $\mathrm{R} 0$ in models for infectious diseases in heterogeneous populations. Journal of mathematical biology 28(4): 365-382

28. Mills CE, Robins JM, Lipsitch M (2004) Transmissibility of 1918 pandemic influenza. Nature 432(7019):904-906

29. Ferguson NM, Cummings DA, Cauchemez S, Fraser C, Riley S, Meeyai A, Burke DS (2005) Strategies for containing an emerging influenza pandemic in Southeast Asia. Nature 437(7056):209-214

30. Chowell G, Miller MA, Viboud C (2008) Seasonal influenza in the United States, France, and Australia: transmission and prospects for control. Epidemiology and infection 136(06):852-864

31. Mao L (2011) Agent-based simulation for weekend-extension strategies to mitigate influenza outbreaks. BMC public health 11(1):522 